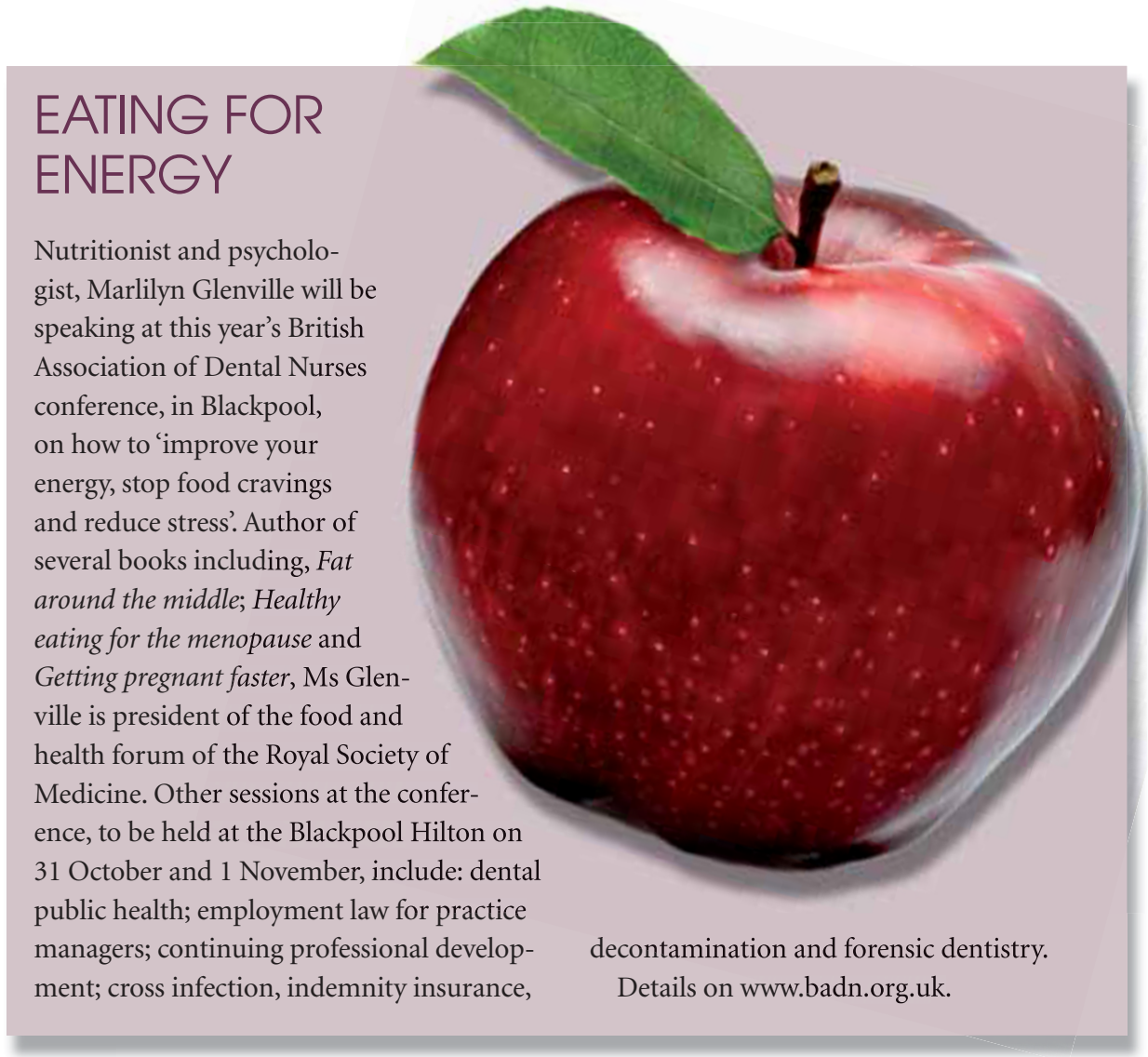

HYGIENISTS AND THERAPISTS CAN WHITEN TEETH, SAYS GDC

Dental hygienists and dental therapists can carry out tooth whitening on the prescription of a dentist, the GDC has advised.

In a statement issued in July the GDC said this was subject to hygienists and therapists having 'the necessary additional skills'. The advice follows a consultation exercise on the scope of practice of the dental team. 'This clarification does not, however, alter the GDC's position that tooth whitening carried out by non-dental professionals is illegal,' said GDC president Hew Mathewson.

The Dental Defence Union (DDU) confirmed that it would provide indemnity insurance for dental therapists and hygienists carrying out tooth whitening.

The GDC has also decided that taking impressions to a dentist's prescription and making bleaching trays to a dentist's prescription are within the scope of dental nurses.

\section{FIRST COURSE FOR CLINICAL DENTAL TECHNICIANS}

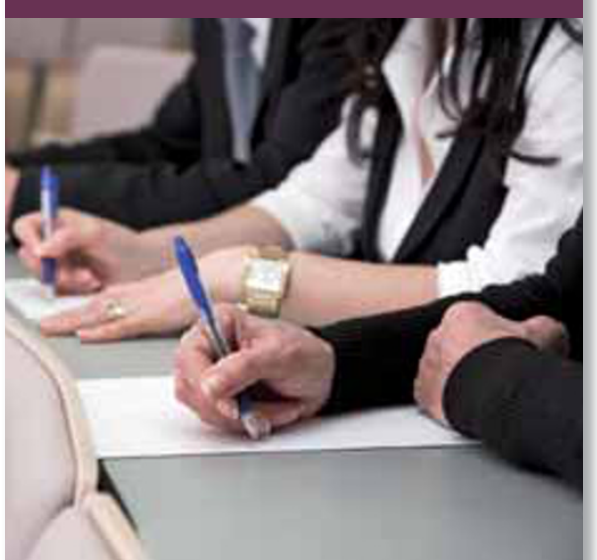

The UK's first stand-alone course for clinical dental technicians has been launched at Edinburgh Dental Institute. The GDC has given provisional approval to the course which consists of three days per week over ten months. Full approval is subject to a visit by the GDC ahead of this year's intake graduating. Applicants must be registered with the GDC as a dental technician and have at least two years' post qualification experience. Those completing the course will be eligible to sit the exam for the diploma in clinical dental technology of the Royal College of Surgeons of Edinburgh.

\section{FIRST ORTHODONTIC THERAPISTS REGISTERED}

All ten students on the UK's first orthodontic therapy course in the UK have passed their diploma and registered with the GDC.

Melanie Bubb, one of the successful participants on the four week course at Leeds Dental Institute, which she described in Vital's winter issue last year, said: 'I am thrilled and proud that we all passed the first ever exam. All the hard work paid off. I am looking forward to treating more patients and seeing my new found skills change their smiles.'

Also successful were: Evelyn Baird, Yvonne Barber, Carol Bentley, Sara Calder, Dawn Lee, Sophie Noske, Becky Shanks, Anne Wiggins and Lisa Woodin.

The role of orthodontic therapist was introduced by the GDC in 2006 when the register for DCPs opened. Applicants must be registered in another DCP role and complete an approved training programme. They are then able, under prescription from a dentist, to carry out a range of duties including taking occlusal records and placing and adjusting fixed appliances.

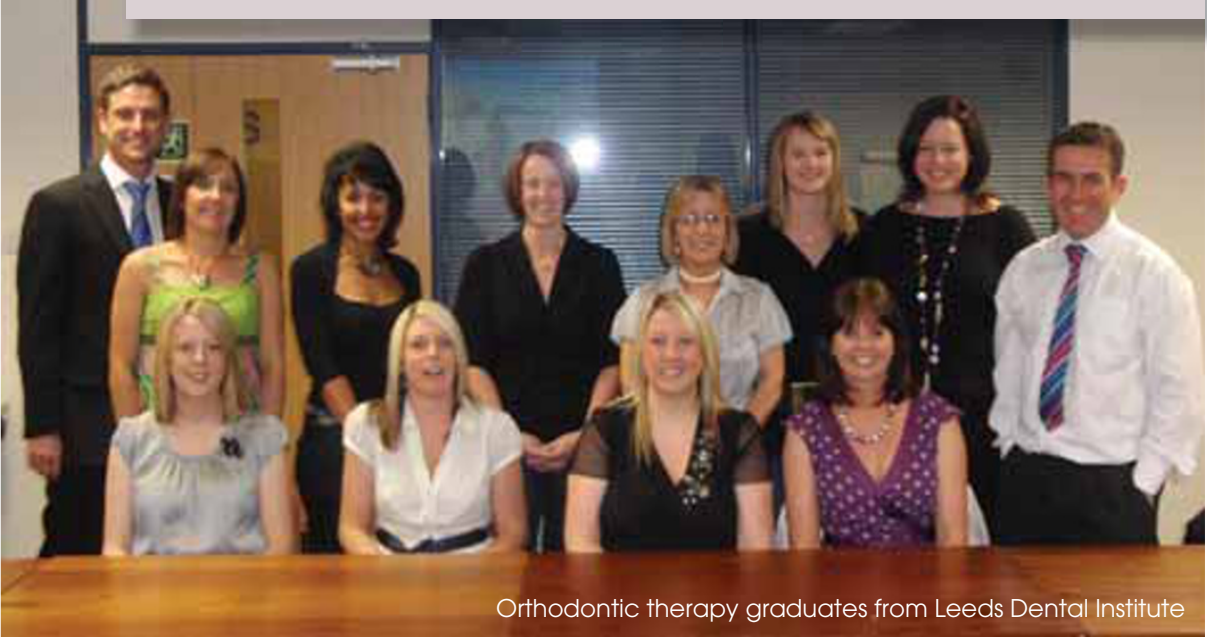

